\title{
Parametric Studies on Desiccant Cooling System for Comfort Cooling
}

\author{
Hemant Parmar ${ }^{1}$, Pranesh Parmar $^{2}$ \\ ${ }^{1}$ Department of Mechanical Engineering, Ujjain Engineering College, Ujjain (M.P.)- India \\ ${ }^{2}$ B.Tech., Mechanical Engineering, Indian Institute of Technology, Mumbai (Maharastra)- India \\ ${ }^{1 *}$ Corresponding Author: e-mail: hemant_parmarl@rediffmail.com \\ ${ }^{2}$ Author: e-mail: praneshparmar99@gmail.com \\ Tel.No. - +91 - 0734 - 2511912 Fax : +91 - 0734- 2511912
}

\begin{abstract}
The necessity of desiccant cooling system has been continuously increasing for protection of the environment and cost associated with the low grade thermal energy. Many feasible sources like solar energy or waste heat are considered for regeneration of the desiccant wheel. The selection of the desiccant cooling system depends on many parameters like cooling load, air flow rate, regeneration temperature, effectiveness of direct evaporative cooler and energy conservation wheel etc. The conventional sizing procedure is more tedious and time consuming. This paper presents some quick sizing methods for different components of desiccant cooling system. Among others components, desiccant wheel is more important component in the system. The size of the desiccant wheel can be estimated by using a simple Nomograph with three parameters. The suggested Nomograph provides a quick solution for designing of the desiccant wheel. Some mathematical models are also presented for estimation of size of direct evaporative cooler, energy conservation wheel, and heater in this paper.
\end{abstract}

Index Terms- Desiccant wheel, regeneration temperature, energy conservation wheel, dehumidification, Nomograph, desiccant calculator.

\section{Nomenclature}

$\mathrm{Q}_{\mathrm{S}}=$ Sensible cooling load, $\mathrm{kW}$

$\mathrm{T}_{\mathrm{S}}=$ Supply temperature ${ }^{\circ} \mathrm{C}$

$\mathrm{T}_{\mathrm{R}}=$ Room temperature, ${ }^{\circ} \mathrm{C}$

$\mathrm{D}=$ Diameter of desiccant wheel, $\mathrm{m}$

$\mathrm{V}=$ Velocity of air, $\mathrm{m} / \mathrm{s}$

$\mathrm{Q}=$ Air flow rate, $\mathrm{m}^{3} / \mathrm{s}$

$\mathrm{m}_{1}=$ Functional modulus for $\mathrm{Q}$ scale

$\mathrm{m}_{2}=$ Functional modulus for $\mathrm{V}$ scale

$\mathrm{m}_{3}=$ Functional modulus for D scale

$\mathrm{a}, \mathrm{b}=$ Position of scale $\mathrm{Q}$ and $\mathrm{V}$ from scale D.

$\Delta \mathrm{p}=$ Fan total pressure rise, $\mathrm{Pa}$

$\eta_{\mathrm{f}}=$ Fan efficiency

$\eta_{\mathrm{m}}=$ Motor efficiency

$\mathrm{C}_{\mathrm{p}}=$ Specific heat of air, $\mathrm{kJ} / \mathrm{kg} \mathrm{K}$

$\mathrm{T}_{1}$ to $\mathrm{T}_{9}=$ Intermediate temperature corresponding to Fig.1.

$\begin{array}{ll}\text { Abbreviations } & \\ \text { DCS } & \text { Desiccant Cooling System } \\ \text { ECW } & \text { Energy Conservation Wheel } \\ \text { COP } & \text { Coefficient of performance } \\ \text { DEC } & \text { Direct evaporative cooler } \\ \text { CFC } & \text { Clorofluorocarbon } \\ \text { kW } & \text { Kilo Watt } \\ \text { eq. } & \text { Equation } \\ \text { No. } & \text { Number } \\ \text { GUI } & \text { Graphical User Interface }\end{array}$

\section{INTRODUCTION}

Desiccant cooling system (DCS) belongs to green technology which provides thermal comfort in humid climate for human being. In humid climate, the

evaporative cooling techniques are not so much effective to provide thermal comfort in residential, commercial or office buildings. The DCS may be suitable option for better use of evaporative cooling 


\section{Available online at www.ijrat.org}

techniques in warm and humid climate. In desiccant cooling system, a desiccant wheel is used for dehumidification of moist air. The dehumidification of air by adsorption is a physical process that attracts the molecules of water present in air on the adsorbent surface. Desiccant materials attract moisture from the air by creating an area of low vapour pressure at the surface of desiccant. Some common adsorbents used are $\mathrm{SiO}_{2}$ (Silica gel), $\mathrm{LiCl}, \mathrm{Al}_{2} \mathrm{O}_{3}$ (Activated alumina), $\mathrm{LiBr}$ and Zeolite. In a typical desiccant cooling system, the moisture (latent load) present in the process air is removed by a desiccant wheel, which has honeycomb structure for passing humid air. A desiccant material impregnated on the inner surface of honeycomb structure. The desiccant wheel is rotated with very slow speed ( 0.5 r.p.m.). When humid air is passed through desiccant wheel, it absorbs moisture and increases temperature of leaving air from the desiccant wheel. The temperature of dehumidified air is reduced by a sensible cooler (e.g. heat exchanger / energy conservation wheel / enthalpy wheel). This sensibly cooled air passed through a direct evaporative cooler (DEC) to obtain desired thermal comfort condition. The desiccant wheel is regenerated by the application of heat to release the moisture, which is exhausted to the outdoors. The heat for regeneration can be supplied from any source such as solar energy, waste heat, natural gas and off peak electricity. A desiccant augmented evaporative cooling system is shown in Fig.1 and their different psychometric processes have been presented in Fig.2.

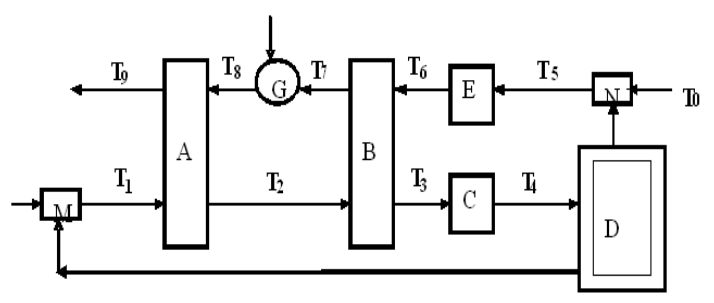

Fig.1- Desiccant Cooling System

(A-Desiccant Dehumidifier, B-Energy conservation wheel for sensible cooling of process air ,C,E-Direct evaporative cooler, D-space required to Conditioned ,M and N-Mixers of air,G-Generator).

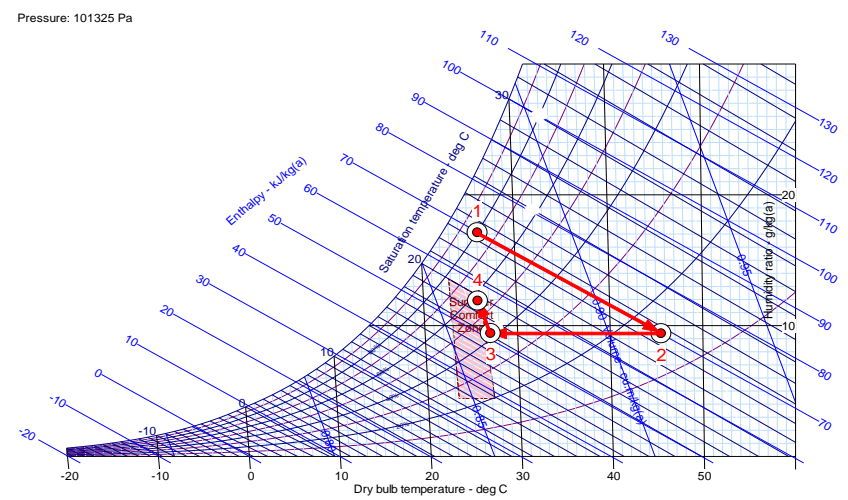

Fig. 2 - Processes of desiccant cooling system on psychometric chart.

The research and development on desiccant cooling systems has been taken up by several researchers. A parametric study of an open - cycle of adiabatic, solid desiccant cooling system analyzed by Charoensupaya and Worek [1] (1988). The effect of non-dimensional dehumidifier channel length, desiccant mass function and desiccant isotherm shapes are investigated. The result yield conditions for which the system has an optimum thermal coefficient of performance. A desiccant wheel applied for low humidity conditions by Subramanayam et al [2] (2004). They explained how the different parameter affects the performance like air flow rate, compressor pumping capacity, speed of wheel etc. and found optimum wheel speed of about $17.5 \mathrm{rpm}$ for high moisture removal and maximum COP. Zhang and Niu [3] (2002) compared the performance of desiccant wheel and drawn the different processes on psychometric chart. Carpinlioglu et al [4] 2004 presents the design and construction of an experimental desiccant cooling system that uses natural zeolite as the desiccant. This is the first use of this desiccant (Natural zeolite) in an actual or experimental system. Panaras G. [5] 2011 identified the main design parameters, and investigates their effect on the performance of the system. Nóbrega and Brum [6] 2011 proposed a design methodology for desiccant cooling cycle, which can be easily carried out graphically on a psychrometric chart. The procedure is then exemplified to analyze the influence of design parameters, such as the steepness of the condition line, over the applicability of desiccant systems.

The calculation of dimensions of all the components of the desiccant cooling system (DCS) is very complicated. Quick sizing methods are hardly available in the previous literature. In this work, a rough method is presented to estimate the required dimensions of main components of desiccant cooling system and some suggestions are provided for sizing of DCS for any ambient conditions. The components of the DCS such as the sensible heat exchanger, direct evaporative cooler and desiccant wheel, as well as operating conditions of outdoor conditions, regenerative temperature and $\mathrm{R} / \mathrm{P}$ ratio have been considered. 


\section{Available online at www.ijrat.org}

\section{SIZE OF DESICCANT COOLING SYSTEM}

Following mathematical equations (Camargo et al [7] 2005) can be used for computing temperatures at intermediate points referring to Fig.1.

Temperature after mixing of return air and outdoor air can be obtained as

$$
T_{1}=x \cdot T_{0}+(1-x) \cdot T_{R 1}
$$

Leaving Temperature $\mathrm{T}_{2}$ and leaving moisture conditions can be estimated by typical performance curve supplied by the manufacturer.

$$
\begin{aligned}
& T_{2}-\varepsilon_{c w}\left(T_{2}-T_{6}\right) \\
& T_{4}=T_{3}-\varepsilon_{D E C}\left(T_{3}-T_{3 w}\right) \\
& T_{6}=T_{5}-\varepsilon_{D E C}\left(T_{5}-T_{5 w}\right) \\
& T_{7}=\left(T_{2}-T_{3}\right) /\left(\frac{R}{P}\right)+T_{6}
\end{aligned}
$$

$T_{8}=$ Temperature of hot air for reactivation of silica gel.

Heat input from the generator to regenerate the desiccant wheel.

$$
\begin{aligned}
& Q_{R}=\left(T_{8}-T_{7}\right) \cdot m_{p} \cdot c_{p} \\
& T_{9}=T_{8}-\left(T_{2}-T_{1}\right) /\left(\frac{R}{P}\right)
\end{aligned}
$$

Equations (1) to (7) of desiccant cooling system are interconnected and can be set a step by step procedure to find the solution. Some parameters are common in above equations and help to calculate the performing parameters of DCS. A calculator has been developed which makes it easy to calculate the unknown parameter of desiccant cooling system from the interconnections of the mathematical equations. Only the DBT, WBT and specific humidity are required for calculating the all intermediate temperatures, heat required for regeneration of the desiccant wheel and COP of the system. The GUI window of desiccant calculator is shown in Fig.3.

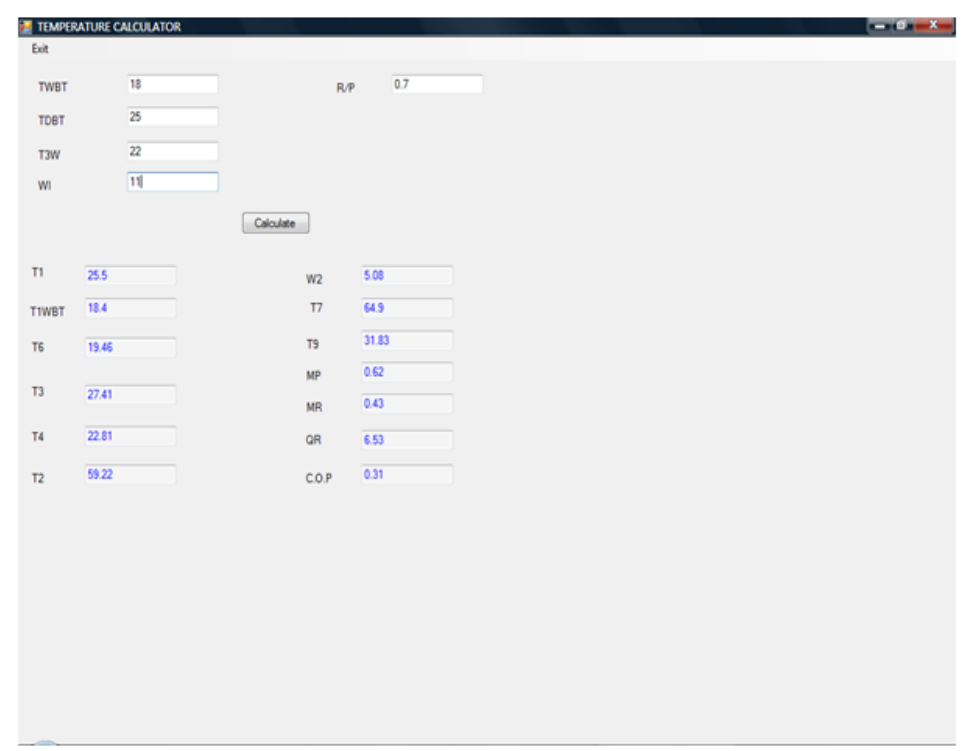

Fig.3 Parameter calculator of desiccant cooling system.

\section{SIZE OF DESICCANT WHEEL}

For the design of the desiccant cooling system, the important input parameter is cooling load in the conditioned space and the ambient conditions. The room condition has to be fixed and cooling load in the room is determined. The sensible cooling load in the room may be expressed by eq. (8) -

$\mathrm{Q}_{\mathrm{S}}=$ Mass flow rate $\mathrm{X} 1.008 \mathrm{X}\left(\mathrm{T}_{\mathrm{S}}-\mathrm{T}_{\mathrm{R}}\right)$

Where $T_{S}$ and $T_{R}$ are the supply temperature from DCS and room temperatures respectively.

The mass flow rate of the air passing through the desiccant wheel is shown in eq. (9) and (10)-

$\mathrm{Q}=\frac{\pi}{4} \mathrm{D}^{2} \mathrm{X}$ Velocity of air $(\mathrm{V})$

Diameter $(D)$ of the desiccant wheel $=\left(\frac{1.27 \times Q}{V}\right)^{1 / 2}$

On the basis of flow rate, a fan can be selected for supplying the correct amount of air. For the selection of the diameter of the desiccant wheel, a parallel scale nomograph was drawn for quick estimation of the size of desiccant wheel. Nomography, truly a forgotten art, is the graphical representation of mathematical relationships or laws. These graphs are variously called nomograms, nomographs, alignment charts, and abacs. For drawing nomograph, the equations (10) and (11) were changed into logarithmic equations (11) and (12).

$\log D=\log \left(\frac{1.27 \times \mathrm{Q}}{\mathrm{V}}\right)^{1 / 2}$

$0.5 \log Q-0.5 \log V=\log D-\log 1.12$

For drawing Nomograph, the range of the flow rate was selected as 0.05 to $0.6 \mathrm{~m}^{3} / \mathrm{s}$ and the velocity of air as 1 to $5 \mathrm{~m} / \mathrm{s}$. The Nomograph contains three 


\section{Available online at www.ijrat.org}

scales Q, V and D. The functional modulus (m) of each scale was determined for the division of the scale within the same height. If the height of the scale considered as $200 \mathrm{~mm}$. The values of functional modulus $m_{1}, m_{2}$, and $m_{3}$ are presented in equations (13), (14) and (15).

The functional modulus $\left(m_{1}\right)$ for the scale $\mathrm{Q}$,

$m_{1}=\frac{200}{(0.5 \log 0.6-0.5 \log 0.05)}=370.71$

The functional modulus for $\mathrm{V}$ scale,

$m_{2}=\frac{200}{(0.5 \log 5-0.5 \log 1)}=573$

The functional modulus for D scale,

$m_{3}=\frac{m_{1} \cdot m_{2}}{m_{1}+m_{2}}=225$

Draw the Q-scale on the left marked off from $Q=0.05$ to $\mathrm{Q}=0.6$ and place tick marks spaced out as $370.71[0.5 \log Q-0.5 \log 0.05]$ which will result in a $200 \mathrm{~mm}$ high line. Then $100 \mathrm{~mm}$ to the right of it we draw the $\mathrm{V}$-scale and the tick marks spaced out on the scale as $573[0.5 \log \mathrm{V}-0.5 \log 1]$. Finally, $40 \mathrm{~mm}$ to the right of the Q-scale we draw the D-scale and tick marks spaced out as 225[ $\log \mathrm{D}-\log 0.1]$. And arrived at the Nomogram on the right, where a straightedge connecting value of $\mathrm{Q}$ and $\mathrm{V}$ crosses the middle scale at the correct solution for $\mathrm{D}$, and in fact any two of the variables will generate the third.

The scale division and the value of the flow rate $(\mathrm{Q})$ are presented in Table 1.

Table 1 Scale divisions and corresponding values of the flow rate of air $(\mathrm{Q})$.

\begin{tabular}{lllllllllllll}
\hline $\mathrm{Q}\left(\mathrm{m}^{3} / \mathrm{s}\right)$ & 0.05 & 0.1 & 0.15 & 0.2 & 0.25 & 0.3 & 0.35 & 0.4 & 0.45 & 0.5 & 0.55 & 0.6 \\
\hline $\mathrm{Sed}$
\end{tabular} \begin{tabular}{lllllllllllll}
\hline Scale divisions & 0 & 55.6 & 88.2 & 111.4 & 129.3 & 144 & 156.4 & 167.2 & 176.6 & 185 & 192.8 & 200
\end{tabular}

For V-scale, the scale divisions are presented in Table 2.

Table 2 Scale divisions and corresponding values of face velocity of air (V).

\begin{tabular}{lccccccccc}
\hline $\mathrm{V}(\mathrm{m} / \mathrm{s})$ & 1 & 1.5 & 2 & 2.5 & 3 & 3.5 & 4 & 4.5 & 5 \\
\hline Scale divisions & 0 & 50.4 & 86.2 & 114 & 136.6 & 155.8 & 172.4 & 187.1 & 200 \\
\hline
\end{tabular}

D-scale divisions are presented in Table 3.

Table 3 Scale divisions and corresponding values of diameters of desiccant wheel (D).

\begin{tabular}{lcccccccc}
\hline $\mathrm{D}(\mathrm{m})$ & 0.1 & 0.2 & 0.3 & 0.4 & 0.5 & 0.6 & 0.7 & 0.8 \\
\hline Scale divisions & 0 & 67.7 & 107.3 & 135.4 & 157.2 & 175 & 190 & 203.1
\end{tabular}

The position of Q-scale is $40 \mathrm{~mm}$ (a) in left and Vscale is $60 \mathrm{~mm}$ (b) right from the D-scale.

The position $\mathrm{a}$ and $\mathrm{b}$ are calculated from the relation presented in equations (16) and (17)-

$\frac{a}{b}=\frac{m_{1}}{m_{2}}$

$a+b=100$

The Nomograph for desiccant wheel is presented in Fig.4.

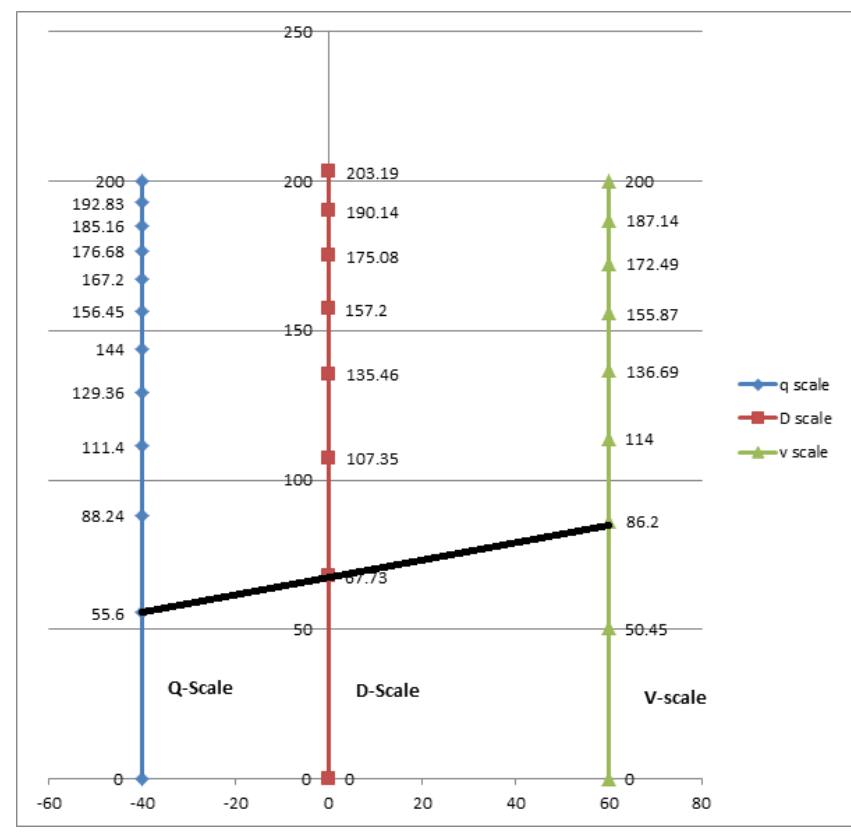

Fig. 4. Nomograph for selection of diameter of desiccant wheel.

For the presented Nomograph, among the three parameters $(\mathrm{Q}, \mathrm{V}$ and $\mathrm{D})$, only two parameters are required to determine the third unknown parameter. e.g. $\mathrm{Q}=0.1 \mathrm{~m}^{3} / \mathrm{s}$ (scale division 55.6 ), $\mathrm{V}=2 \mathrm{~m} / \mathrm{s}$ (scale division 86.2). The line crossing the D-scale on scale division of 67.73 and the corresponding value of diameter of desiccant wheel is $0.2 \mathrm{~m}$.

\section{DIRECT EVAPORATIVE COOLER}

Evaporative cooler is used for mixing of correct amount of moisture to the conditioned space for thermal comfort. Direct evaporative coolers are the simplest and lowest first cost approach to evaporative cooling. Direct cooling contributes the maximum moisture fraction to supply air, producing a different quality of cooling than vapour compression system that tends to dehumidify, even under dry indoor conditions. The supply air temperature can be calculated assuming a constant effectiveness of a DEC.

The fan power of DEC can be estimated by the equation (18)-

$$
\begin{aligned}
& \text { Fan power }\left(\mathrm{P}_{\mathrm{f}}\right) \\
& =\frac{\mathrm{Q} * \Delta \mathrm{P}}{1000 * \eta_{f} * \eta_{m}}
\end{aligned}
$$

Where $\mathrm{Q}=$ Volumetric flow rate in process air, $\mathrm{L} / \mathrm{s}$

$\Delta \mathrm{P}=$ Fan total pressure rise, $\mathrm{Pa}$

$\eta_{f}=$ Fan efficiency

$\eta_{m}=$ Motor efficiency

\section{HEATER POWER}

Heater is used for supplying hot air at regeneration temperature of desiccant wheel. When return air is used in the heater input, less power is used to increase 


\section{Available online at www.ijrat.org}

the temperature of air. The heater power can be calculated by equation (19)-

$Q_{h}=m_{r} * c_{p} *\left(T_{8}-T_{7}\right)$

Where $m_{r}=$ Mass flow rate of Air in regeneration side, $\mathrm{kg} / \mathrm{s}$

$c_{p}=$ Specific heat of air, $\mathrm{kJ} / \mathrm{kgK}$

$T_{8}=$ Regeneration temperature, $\mathrm{K}$

$T_{7}=$ Cycle return air in regeneration side, $\mathrm{K}$

The solar energy can be used for regeneration of desiccant wheel. Solar air heater can be used for supplying the hot air and regenerate the desiccant wheel.

Industrial waste heat can also utilize for the regeneration of desiccant wheel. Hot flue gases of the boiler are used to supply in the desiccant wheel for regeneration.

\section{ENERGY CONSERVATION WHEEL (ECW)}

For the selection of the energy conservation wheel, the graphical standard curves and tables are available which are supplied by the manufacturer. The ECW is a rotary counter flow air-to-air heat exchanger capable of transferring both sensible and latent (enthalpy) heat between air streams. The wheel rotates between two streams i.e. process air and return air. For the air ratio 1 , the air flow rate on both the sides (i.e. process and return air side) should be same. On the basis of the air flow rate, an ECW is selected.

\section{CONCLUSIONS}

This paper presents the simplest way to obtain the basic parameters of the main components of desiccant cooling system. A graphical technique i.e. Nomograph is presented for quick estimation of the diameter of desiccant wheel. If process air flow rate and face velocity of air is known then with the help of Nomograph, the required diameter of desiccant wheel can be estimated. On the basis of the fan power of direct evaporative cooler (DEC), the size of the DEC has to be decide. The size of the required heater for regeneration of the desiccant wheel is estimated by providing the regeneration temperature of given desiccant material and temperature of air from return line of regeneration side. A GUI based desiccant calculator was developed to obtain quick performance of Desiccant Cooling System.

\section{Acknowledgments}

The authors would like to thank the Department of Mechanical Engineering, Ujjain Engineering College, Ujjain (M.P.) - India for support and help to complete this work. Author also thank to Dr. Vijay Kumar Hinge, Dr. Lokendra S. Thakur and Prof. K.S. Solanki for their support and assistance in this work.

\section{REFERENCES}

[1] Charoensupaya, D. and Worek, W. M., Effect of adsorbent heat and mass transfer resistances on performance of an open-cycle adiabatic desiccant cooling system. Heat Recovery Systems and CHP, 1988, 8 (6): 537-548.

[2] Subramanyam, N., Maiya, M.P. and Murthy, S.S., Application of desiccant wheel to control humidity in air conditioning system. Applied Thermal Engineering, 2004, 24: 2277-2788.

[3] Zhang,L.Z. and Niu,J.L., Performance comparisons of desiccant wheels for air dehumidifier and enthalpy recovery. Applied Thermal Engineering,2002,22: 1347-1367.

[4] Carpinlioglu, M.O., Yildirim, M., Kanoglu, M., Experimental study on an open cycle desiccant cooling system. International journal of Exergy,2004, 1 (2): 268-288.

[5] Panaras, G., Mathioulakis, E., Belessiotis, V., Solid desiccant airconditioning systems- design parameters. Energy,2011, 36 (5): 2399-2406.

[6] Nóbrega, C.E.L. and Brum, N.C.L., A graphical procedure for desiccant cooling cycle design. Energy,2011, 36 (3): 1564-1570.

[7] Camargo J.R., Godoy E. Jr., binuma, C.D., An evaporative and desiccant cooling system for air conditioning in humid climates. Journal of the Brazil Society of Mech. Sc. And Engg.,2005,Vol.XXVII,No.:3/243. 